\title{
Risk Factors for Fouling Biomass: Evidence from Small Vessels in Australia
}

\author{
Tracey Hollings ${ }^{1}$, Stephen E. Lane ${ }^{1}$, Keith R. Hayes ${ }^{2}$, Felicity R. \\ McEnnulty ${ }^{3}$, Mark Green ${ }^{3}$, Eugene Georgiades ${ }^{4}$, and Andrew P. \\ Robinson $^{1}$
}

${ }^{1}$ Centre of Excellence for Biosecurity Risk Analysis, The University of Melbourne

${ }^{2}$ Data61, Commonwealth Scientific and Industrial Research Organisation

${ }^{3}$ Oceans and Atmosphere, Commonwealth Scientific and Industrial Research Organisation ${ }^{4}$ Ministry for Primary Industries, New Zealand

March 21, 2018

\begin{abstract}
Invasive marine non-indigenous species are a major threat to marine biodiversity and marine related industries. Recreational vessels are recognised as an important vector of non-indigenous species translocation, particularly the secondary translocation of species domestically.

This paper reports on a novel application of multilevel modelling and multiple imputation to biomass samples gathered from the hull and other external surfaces of recreational yachts and fishing vessels in order to quantify the relationship between the wet biomass of biofouling and vessel-level characteristics. Unsurprisingly, we find that the number of days since the vessel was last cleaned was strongly related to the wet weight of biomass. The number of days since the vessel was last used was also related to the wet weight of biomass, yet differed depending on the vessel type. Similarly, the median number of trips undertaken by the vessel was related to the wet weight of biomass, and varied according to the type of antifouling paint used by the vessel. The relationship between vessel size, as measured by hull surface area, and wet weight biomass per sample unit area was not significant.

In order to reduce the international and domestic spread of invasive species, small vessel owners should use an appropriate type of antifouling paint that suits their vessel's operational profile, and be encouraged to maintain a maintenance
\end{abstract}


bioRxiv preprint doi: https://doi.org/10.1101/248567; this version posted May 11,2018 . The copyright holder for this preprint (which was not certified by peer review) is the author/funder, who has granted bioRxiv a license to display the preprint in perpetuity. It is made available under aCC-BY-NC 4.0 International license.

schedule in accordance with the paint manufacturer's specifications.

\section{Introduction}

Invasive marine non-indigenous species are a major threat to marine biodiversity leading to dramatic shifts in population, community and ecosystem dynamics, and many have serious environmental and economic implications (Carlton and Geller, 1993; Ruiz et al., 1997; Vitousek et al., 1996). Vessel biofouling is a significant pathway for the introduction and spread of marine non-indigenous species globally (Molnar et al., 2008; Georgiades and Kluza, 2017), effectively removing natural barriers to dispersal, including ocean currents and distance (Paini and Yemshanov, 2012; Ruiz et al., 1997). Since Carlton and Geller (1993), knowledge of invasion processes and pathways for nonindigenous species in marine environments has developed considerably. International policies have been developed to regulate the ballast water pathway (International Maritime Organization, 2017) and guidelines have been developed to minimize the spread of biofouling (International Maritime Organization, 2011; International Maritime Organization, 2012). Biofouling regulations have recently been put in place by New Zealand, California and Western Australia. Because international regulation of the biofouling pathway is still relatively new, the domestic spread of non-indigenous species via this pathway, though recognised (Inglis et al., 2013; Sinner et al., 2013), remains largely unregulated. The secondary spread of non-indigenous species will ultimately determine the magnitude of economic and environmental damage caused by invasive species (Zabin et al., 2014).

42 The role of recreational vessels as vectors for the introduction (Ashton et al., 2014; Clarke Murray et al., 2011; Minchin et al., 2006) and spread (e.g. Burgin and Hardiman, 2011; Clarke Murray et al., 2011; Hewitt et al., 2007; Lacoursière-Roussel et al., 2012a; Minchin et al., 2006) of non-indigenous species has long been recognised. Impacts from invasive marine non-indigenous species are likely to increase with increasing use of the marine environment; for example, via the growth of marine aquaculture and increases to ship-borne trade or development of new trade routes (Hulme, 2009; Food and Agriculture Organization of the United Nations, 2016; International Maritime Organization, n.d.). In Australia, impacts from secondary invasions may become more likely as recreational vessel ownership continues to increase. In the decade from 1999-2009 vessel ownership increased by more than $36 \%$ to over 800,000 individual registered vessels nationwide (Burgin and Hardiman, 2011).

Recreational vessels have been implicated in several high profile and significantly damaging incursions of non-indigenous species including the introduction of the black 
bioRxiv preprint doi: https://doi.org/10.1101/248567; this version posted May 11, 2018. The copyright holder for this preprint (which was not certified by peer review) is the author/funder, who has granted bioRxiv a license to display the preprint in perpetuity. It is made available under aCC-BY-NC 4.0 International license.

striped mussel (Mytilopsis sallei) into a recreational marina in Darwin, Australia in 1999.

Strong evidence suggests it was introduced by hull fouling on an international yacht, and detections of the mussel outside of the marina were traced to movement of smaller vessels. M. sallei has similar ecological and morphological characteristics to the freshwater zebra mussel (Dreissena polymorpha) and, at the time of discovery, densities were as high as 24,000 per square metre (Thresher, 1999). The Darwin incursion was successfully eradicated due to the fact that the mussel was contained within marinas with lock gates due to the 8 metres tidal fall (Willan et al., 2000). This situation is unlike the majority of eradication attempts of other marine non-indigenous species that have ultimately failed often despite concerted efforts. The inherent difficulties of marine invasion control has led to a focus on reducing the human-mediated spread of nonindigenous species from major ports via high risk transport vectors (Drake and Lodge, 2004; Floerl et al., 2005; Forrest and Hopkins, 2013; Georgiades and Kluza, 2017). Recreational craft may constitute a significant portion of these vectors (Inglis et al., 2012).

Biofouling is a significant pathway for introduction of marine non-indigenous species for both commercial and recreational vessels (Acosta et al., 2010; Hewitt et al., 2004; Inglis et al., 2012; Minchin et al., 2006; Thresher, 1999). Studies of international and domestic recreational vessels have demonstrated a range of fouling rates, with most surveys showing that over $50 \%$ of vessels, and sometimes as high as $80 \%$, having some level of fouling (Ashton et al., 2014; Floerl et al., 2005; Lacoursière-Roussel et al., 2012b; Minchin et al., 2006; Zabin et al., 2014). The extent of fouling on any individual vessel, however, is often highly variable, irrespective of sample sizes and methodology (Ashton et al., 2014; Brine et al., 2013; Clarke Murray et al., 2011; Floerl et al., 2005). Some areas on a vessel are inherently more susceptible to fouling due to different hydrodynamic forces, susceptibility to coating system wear or damage, or being inadequately (or not) painted (International Maritime Organization, 2011). These "niche" areas contribute to fouling variability as they can have considerably higher levels of fouling than the hull (Lacoursière-Roussel et al., 2012b) and include internal water systems and intake pipes, rudder, propeller, and anchors/chain cabinets (Acosta et al., 2010; Burgin and Hardiman, 2011; Hewitt et al., 2007; Minchin et al., 2006).

Characteristics of recreational vessels that increase both the rate and extent of fouling are substantially different to those of commercial vessels (Lacoursière-Roussel et al., 2012b). Small vessels can have irregular maintenance and cleaning schedules, may spend significant amounts of time in port where opportunities for colonisation are so high, travel at low speeds, and have varied presence and abundance of niche areas (Brine et al., 2013; Clarke Murray et al., 2011; Floerl et al., 2005; Minchin et al., 2006). Considerable variation in vessel usage and maintenance means there is equally likely 3 to be variation in transport frequency and likelihood of non-indigenous species spread 
(Floerl et al., 2005). Recreational vessels often visit pristine and often protected marine areas which may be highly susceptible to invasive marine species and disconnected from commercial shipping ports and aquaculture (Clarke Murray et al., 2011; Georgiades and Kluza, 2017). Further, recreational vessels pose an additional risk of nonindigenous species transfer to aquaculture sites (Sim-Smith et al., 2016).

Vessel movements are not without risk; minimising translocation of species requires a relevant and transparent risk based profiling and assessment (Campbell and Hewitt, 2011); such assessments have been proposed in Australia as part of regulatory interventions to manage biofouling risk (Piola and McDonald, 2012; Clarke et al., 2017; Lott and Rose, 2016). If specific attributes of small vessels can be identified which increase fouling biomass and therefore facilitate the movement of non-indigenous species, then management actions and regulations can be implemented by authorities to could reduce their spread and impacts.

Using modern statistical modelling, this paper aims to identify characteristics of recreational vessels which potentially increase the extent of fouling biomass. While several studies have estimated fouling extent on a measure or index of in situ fouling cover (e.g. Ashton et al., 2006; Brine et al., 2013; Floerl et al., 2005), this paper offers an alternative methodology to determine vessel characteristics which influence fouling extent; that is, on directly measured fouling biomass.

Moreover, the methods which we use deal directly with the complexities of the twostage sampling approach used to collect the data. Our data comprises samples collected from the hull and niche areas of small vessels from five locations in south-east Australia, along with vessel-level characteristics, including transport and maintenance history. The resulting data consists of two levels: multiple wet weight biomass measurements are collected for each vessel. Complicating analysis is the fact that some vessel-level characteristics are missing.

The rest of the paper proceeds as follows: in Section 2 we provide details on the data and the statistical models used for analysis; in Section 3 we present the results in detail for the full modelling procedure; and in Section 4 we provide a discussion of the results. 


\section{Methods}

\subsection{Data}

The data used in this paper came from an exploratory survey in Australia conducted by the Commonwealth Scientific and Industrial Research Organisation's (CSIRO) Centre for Research on Introduced Marine Pests (CRIMP). Biomass samples were collected from 54 vessels $^{1}$ at 5 geographical locations during the project. All vessels were selected based on convenience when pulled out of the water for maintenance; access and permission was gathered from owners via the Bosun and slipway managers at each of the sites.

Samples were collected from both external and internal surfaces using plastic and metal putty knives, immediately following the vessels removal from the water. All samples were washed with $0.2 \mu \mathrm{m}$ filtered seawater, sieved to remove as much excess water as possible, and subsequently weighed using Sartorius BL3100 scales. Due to the unreliability of low wet weight measurements, samples that weighed less than 1.5 $\mathrm{g}$ were assigned a biomass of $0.5 \mathrm{~g}$; that is, the lower limit of detection was $1.5 \mathrm{~g}$.

Most vessels were sampled in Hobart, Tasmania, Australia at the Royal Hobart Yacht Club (17) and the Domain Slipyard (16). The remaining vessels were sampled in Melbourne, Victoria, Australia at the Sandringham Yacht Club (14), the Hobsons Bay Yacht Club (4), and the Royal Yacht Club of Victoria (2). Most of the sample vessels were yachts (31), followed by commercial fishing vessels (12), motor cruisers and others (10).

Samples were collected from as many as 64 different locations in and around the hull, propeller, rudder and anchor, internal spaces, fishing gear and deck of the vessels. Samples taken from the hull ${ }^{2}$, fixed keel and rudder surface were consistently collected using $0.5 \mathrm{~m}^{2}$ quadrats, so these form the focus of our analysis. There were 252 samples collected from the hull, 94 from the rudder surface, and 74 from the fixed keel; in all, 420 samples were taken. The number of samples collected per vessel ranged from 6 to as many as 10; most vessels (41) were sampled 8 times.

Vessel-level data collected from owners included: dimensions of the vessel; the type of antifouling paint applied (ablative, hard, and self-polishing); voyage history (number of days since the vessel was last used, median number of trips per year); the number of days since the vessel was last cleaned or antifouled; the surface area of the hull $\left(\mathrm{m}^{2}\right)$; and the type of vessel (yacht, fishing, motor cruiser and others). Table 1 shows

\footnotetext{
${ }^{1}$ One vessel was removed from analysis due to its abnormally high biomass measurements.

${ }^{2}$ Fore, midships and aft were all sampled, both port and starboard.
} 
summary statistics for these observed characteristics.

For more details on the data collected during the survey, see Australian Government

Natural Heritage Trust Project 46630 (Hayes et al., 2007).

Table 1: Summary statistics for vessel-level characteristics. Categorical variables are shown as $\mathrm{n}(\%)$, and numeric variables are shown as median (interquartile range, IQR).

\begin{tabular}{llr}
\hline & Variable & $\mathrm{n}(\%) /$ median (IQR) \\
\hline Vessel type & Fishing & $10(19 \%)$ \\
& Motor cruiser/Other & $12(23 \%)$ \\
& Yacht & $31(58 \%)$ \\
\hline Paint type & Ablative & $21(40 \%)$ \\
& Hard & $12(23 \%)$ \\
& Self-polishing & $15(28 \%)$ \\
& Missing & $5(9 \%)$ \\
\hline \multirow{2}{*}{ Numeric variables } & & \\
& Hull surface area (m $\left.{ }^{2}\right)$ & $42.0(28.0,57.0)$ \\
& Days since last used & $12.0(4.0,78.0)$ \\
& Days since last cleaned & $249.0(79.0,352.0)$ \\
& Trips per year & $17.2(10.4,45.6)$ \\
\hline
\end{tabular}


bioRxiv preprint doi: https://doi org/101101/248567; this version posted May 11, 2018. The copyright holder for this preprint (which was not certified by peer review) is the author/funder, who has granted bioRxiv a license to display the preprint in perpetuity. It is made available under aCC-BY-NC 4.0 International license.

\subsection{Statistical Analysis}

Figure 1 shows histograms of the observed wet weight of biomass from the samples.

Samples that were below the limit of detection (1.5 g, of which there were 101) are not shown in this figure. The left column shows the measured wet weight, whilst the right column shows the log-transformed wet weight; the rows correspond to the sampled locations on each vessel (hull, keel and rudder).
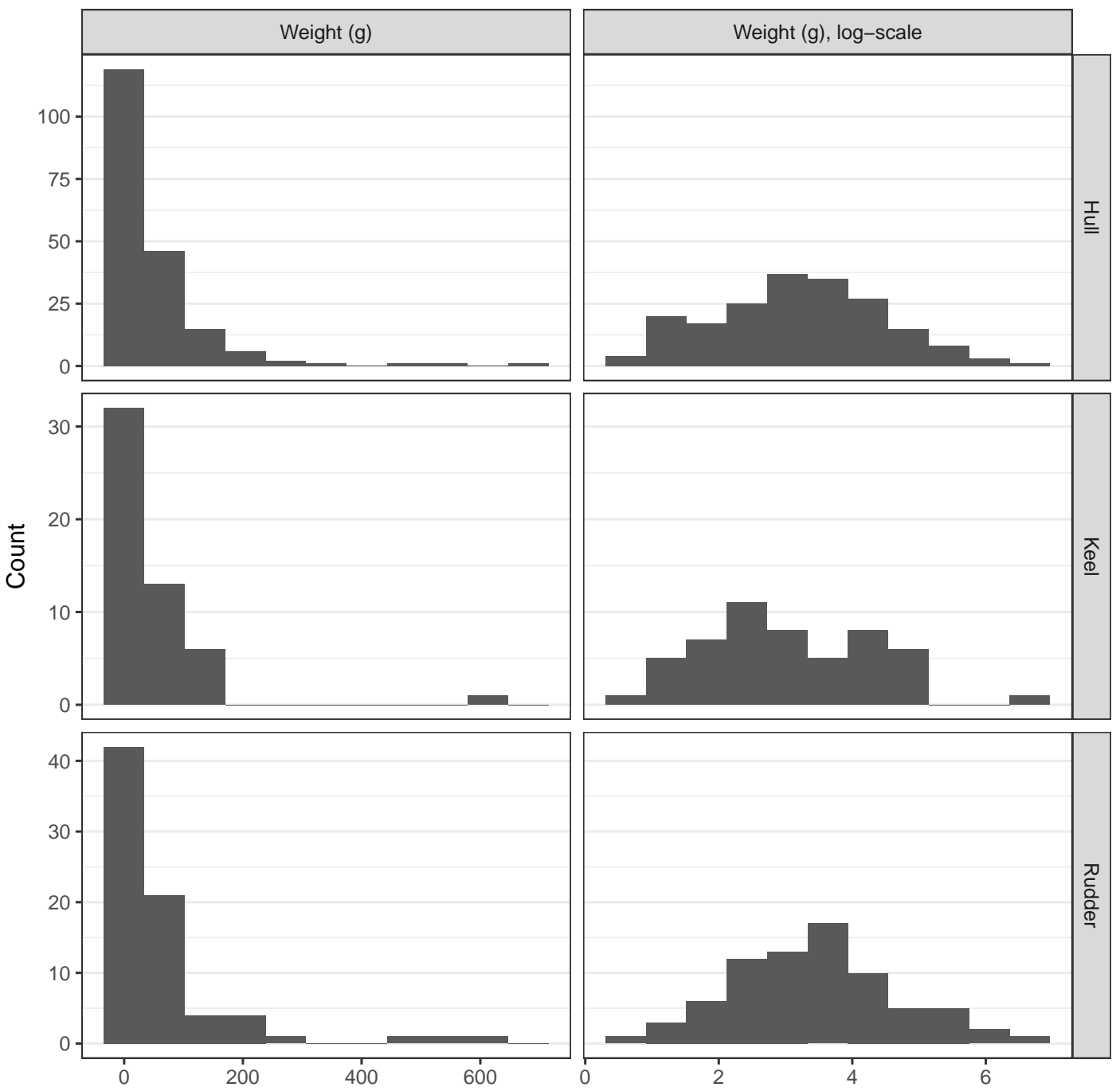

Figure 1: Measured wet weight of sampled biomass from the 53 vessels. The left column shows the measured wet weight, whilst the right column shows the log-transformed wet weight. Samples that measured less than the limit of detection $(1.5 \mathrm{~g})$ have been removed.

Figure 1 suggests that the log-transform of the wet weight of biomass has an approximately Normal distribution, and that there is likely to be a location effect (most notably between Hull versus Keel and Rudder). We thus focus on a log-transform of the wet weight of biomass for the remainder of the analysis. Further, there appears to be the possibility of outliers, especially within the hull and rudder samples. Hence we will 
also consider a Student- $t$ distribution for modelling.

It could be tempting to analyse the total (or average) wet weight biomass per vessel, as this would simplify the modelling procedure. However, as noted above, Figure suggests that the wet weight of biomass varies with the location from which a sample was taken; hence averaging will mask this variation. Further, the variable number of samples taken per vessel (Section 2.1) means that the total biomass may be dependent upon the number of samples taken. For these reasons, we chose to use a multilevel regression model, in which a modelled intercept allows for the repeated measurements within vessels, whilst also allowing investigation of vessel-level relationships.

To allow for the possible effects of outliers we examined the effect of changing the outcome (or observation) model from Normal to Student- $t$. Let $Y_{i}$ be the log wet weight of biomass for the $i^{\text {th }}$ observation, $i=1, \ldots, 420$. Then:

$$
\begin{aligned}
Y_{i} & \sim \operatorname{Normal}\left(\mu_{i}, \sigma\right) \\
Y_{i} & \sim t_{\nu}\left(\mu_{i}, \sigma\right) \\
\nu & \sim \operatorname{Gamma}(2,10)
\end{aligned}
$$

where $\mu_{i}$ is the expected log wet weight in grams; $\mu$ is the intercept for the model; $\beta_{l}$ are coefficients that measure the effect of location on the log wet weight of fouling biomass: $l=1$ denotes the measurement was taken at the hull, $l=2$ denotes the measurement was taken at the rudder, and $l=3$ for measurements taken at the keel ${ }^{3} . \alpha_{j}$ is the

\footnotetext{
${ }^{3}$ The notation $l[i]$ denotes the location level $(l)$ of the $i^{\text {th }}$ observation. The vessel-level intercept $\left(\alpha_{j[i}\right)$
} 
vessel-level intercept that allows the hull intercept to vary from vessel to vessel, $j=$ $1, \ldots, 53$, which is modelled as a $t$ distribution with 3 degrees of freedom, and scale $\sigma_{l}$. The intercept is given a weakly informative $N(0,5)$ prior. Similarly the regression coefficients are given weakly informative $t_{3}(0,1)$ priors; as are the observation model and latent process scale parameters using half-Cauchy $(0,2.5)$ priors.

We subsequently investigated two alternative specifications for the vessel-level intercept by including various vessel-level characteristics and interaction terms:

$$
\begin{aligned}
& \mu_{i}=\mu+\gamma_{j[i]}+\beta_{l[i]} \\
& \gamma_{j}^{*}=\alpha_{j}+\beta_{d 1} \cdot \text { days }_{j}+\beta_{d 2} \cdot \text { days }_{j}+\beta_{m} \cdot \text { midTrips }_{j}+\beta_{h} \cdot \text { hullSA }_{j}+\beta_{p[j]}+\beta_{t[j]} \\
& \gamma_{j}^{*}=(\mathrm{M} 1)+\beta_{d t[j]} \cdot \text { days }_{j}+\beta_{m t[j]} \cdot \text { midTrips }_{j}+\beta_{m p[j]} \cdot \text { midTrips }_{j}
\end{aligned}
$$

M1 includes all vessel-level characteristics, where days $1_{j}$ is the number of days since vessel $j$ was last used; days $2_{j}$ is the number of days since the vessel was last cleaned; midTrips $_{j}$ is the median number of trips undertaken by the vessel per year; and hullSA ${ }_{j}$ is the hull surface area. $\beta_{p[j]}$ is the effect of paint type $p$ on vessel $j, p=1$ denotes ablative paint, $p=2$ denotes hard paint, and $p=3$ denotes self-polishing antifouling paint. $\beta_{t[j]}$ is an effect for vessel type; $t=1$ denotes motor cruiser/other, $t=2$ denotes fishing vessels, and $t=3$ denotes yachts. M2 adds interaction terms to M1 between: the number of days since the vessel was last used and the vessel type $\left(\beta_{d t[j]}\right)$; the median number of trips and the vessel type $\left(\beta_{m t[j]}\right)$; and the median number of trips and the paint type $\left(\beta_{m p[j]}\right)$.

The choice of these regression models was guided by both subject matter/process considerations and graphical exploration of the posterior distribution of the random-effect terms in the latent process models. For more details on the graphical exploration, see Section 3.

\subsection{Missing Data}

There is missing data at the vessel level; Table 2 displays the observed data pattern, shown as (Days since last used, Paint type, Days since last trip), where a 1 denotes the variable is observed, and a 0 denotes the variable is missing. For example, Table 2 shows there are 41 observations with complete vessel-level data, and 1 observation that is missing all measurements of days since last used, paint type, and days since last trip.

is similarly referenced. 
A complete-case data analysis would only utilise $77.4 \%$ of the vessel-level data, and subsequently, this would result in 324 (77.1\%) measurements of wet weight biomass being available for the complete-case analysis at the measurement (first) level.

Because of the amount of missing data, we used multiple imputation to impute the missing vessel-level data. Specifically, we used iterative conditional imputation, with all vessel-level variables used in the imputation specification; to account for any nonlinearities, random forest imputation was used.

As all missing data was at the vessel-level, we used the median wet weight of biomass as a predictor in the imputation models (Gelman and Hill, 2007). To account for the censoring in the wet weight of biomass (observations below the $1.5 \mathrm{~g}$ limit of detection), we replaced the censored data by a random draw from a Uniform $(0,1.5)$ distribution. We justify this procedure in the following way: i) some level of variability is required as we don't know the true value of the censored observations; ii) Figure 1 shows that weights below $1.5 \mathrm{~g}$ ( 0.4 on the log-scale) form a very small part of the range of observed values. This small variability will have limited impact in the imputation of the missing data due to the fact that we are summarising within-vessel wet weight of biomass measurements by the median for input into the imputation models.

To perform inference, we follow the advice of Zhou and Reiter (2010) and mix the draws from the posterior distributions from the analysis of each completed dataset ${ }^{4}$. Zhou and Reiter (2010) recommend a large number of imputations be used; we generated 50 imputed datasets. For each dataset, 2000 samples were drawn from the posterior after a burn-in of 2000. Convergence was monitored by inspecting the mixed chains across the 50 multiple imputations, and by assessing the Gelman-Rubin statistic (Gelman and Rubin, 1992).

Table 2: Observed data pattern for vessel-level characteristics. The patterns are shown as (Days since last used, Paint type, Days since last trip), where a 1 denotes the variable is observed, and a 0 denotes the variable is missing. A count of each type of pattern is shown.

\begin{tabular}{lr}
\hline Observed data pattern & Count \\
\hline$(1,1,1)$ & 41 \\
$(0,1,1)$ & 1 \\
$(1,1,0)$ & 5 \\
$(1,0,1)$ & 4 \\
$(0,1,0)$ & 1 \\
$(0,0,0)$ & 1 \\
\hline
\end{tabular}

\footnotetext{
${ }^{4}$ The alternative would be to combine posterior estimates of summary parameters using Rubin's rules (Rubin, 1996), which necessarily gives point estimates as opposed to full posterior distributions.
} 
All analyses were performed using $\mathrm{R}$ version 3.4.0 ( $\mathrm{R}$ Core Team, 2017); the multilevel models were fit using the RStan interface to Stan (Stan Development Team, 2016), and multiple imputation was performed using the R package mice (Buuren and Groothuis-Oudshoorn, 2011). R code and data to reproduce the analysis may be found at https://github.com/SteveLane/blistering-barnacles.

\section{Results}

\subsection{Multiple Imputation}

Visual comparison between the observed and imputed data suggests that the imputation procedure has satisfactorily converged, i.e. there was no large discrepancies between the imputed data and the observed. The comparison between observed and imputed data is presented in the Supplemental Material.

\subsection{Outcome Model}

The $t$-distribution observation model $(\mathrm{O} 2)$ outperformed the Normal distribution observation model (O1). The difference in the leave-one-out information criterion (LOOIC, analogous to AIC, see Vehtari et al., 2016) was 47 (standard error 13) in favour of the $t$-distribution observation model (O2).

Posterior predictive checks likewise confirmed the superiority of the $t$-distribution observation model. Graphical checks were made using the proportion of posterior predictions that lie below the limit of detection; the median posterior predictions and the interquartile range (IQR) of the posterior predictions. The graphical checks and LOOIC comparisons can be found in full in the Supplemental Material.

\subsection{Regression Results}

\subsubsection{Exploration of Candidate Interaction Terms}

Figure 2 displays the posterior median and $80 \%$ credible intervals of the regression coefficients in the vessel-level intercept models (for each of the four ordinal predictors

- the number of days since the vessel was last used; the number of days since the vessel was last cleaned; the median number of trips undertaken by the vessel; and the vessel's hull surface area). Figure 2a shows the coefficients coloured by vessel type, 
whilst Figure $2 \mathrm{~b}$ shows the coefficients coloured by antifouling paint type. Each panel also shows the posterior (median) estimate of the expected log wet weight from model M1, and is based on a randomly selected imputed dataset for display purposes.

Figures $2 \mathrm{a}$ and $2 \mathrm{~b}$ are suggestive of interactions between the number of days since the vessel was last used and the vessel type, the median number of trips undertaken by the vessel and the vessel type, and the median number of trips taken by the vessel and the antifouling paint type. We form this opinion by visual comparison of the scatterplots. For example, the pattern in Figure 2a suggests that the effect of days since the vessel was last used is negative for fishing vessels and positive for yachts and motor cruiser/other vessels. Similarly, the effect of the median number of trips undertaken by the vessel appears to be positive for fishing vessels, and negative for yachts and motor cruiser/other vessels.

\subsubsection{Final Model Form}

Figure 3 displays the median and $80 \%$ intervals of the estimated vessel-level intercepts, with respect to the two ordinal predictors used in interaction terms in (M2): the number of days since the vessel was last used and the median number of trips (per year) undertaken by the vessel. Figure 3 a shows the vessel-level intercepts coloured by vessel type and Figure 3b shows the vessel-level intercepts coloured by antifouling paint type. Shown in each panel are the estimated (median) regression lines from M2.

Figure 3a suggests that the of the number of days since the vessel was last used varies by vessel type, as does the median number of trips taken by the vessel per year. Figure $3 \mathrm{~b}$ further suggests that the effect of the median number of trips taken by the vessel per year varies according to the paint type of the vessel. The uncertainty in these effects is however, large relative to the estimates.

1 Figure 4 compares estimates of the measurement-level and vessel-level regression coefficients for each of the models considered. As can be seen in Figure 4, the effect of the number of days since the vessel was last cleaned $\left(\beta_{d 2}\right)$ is clearly larger than 0 ; the other predictors do not appear to have such a strong effect. Whilst the effect of these predictors is not estimated precisely, the direction and size of the coefficients is similar between models, and as such we choose Model (M2) as the final model form in order to estimate the interactions. 
bioRxiv preprint doi: https://doi.org/10.1101/248567; this version posted May 11, 2018. The copyright holder for this preprint (which was not certified by peer review) is the author/funder, who has granted bioRxiv a license to display the preprint in perpetuity. It is made available under aCC-BY-NC 4.0 International license.

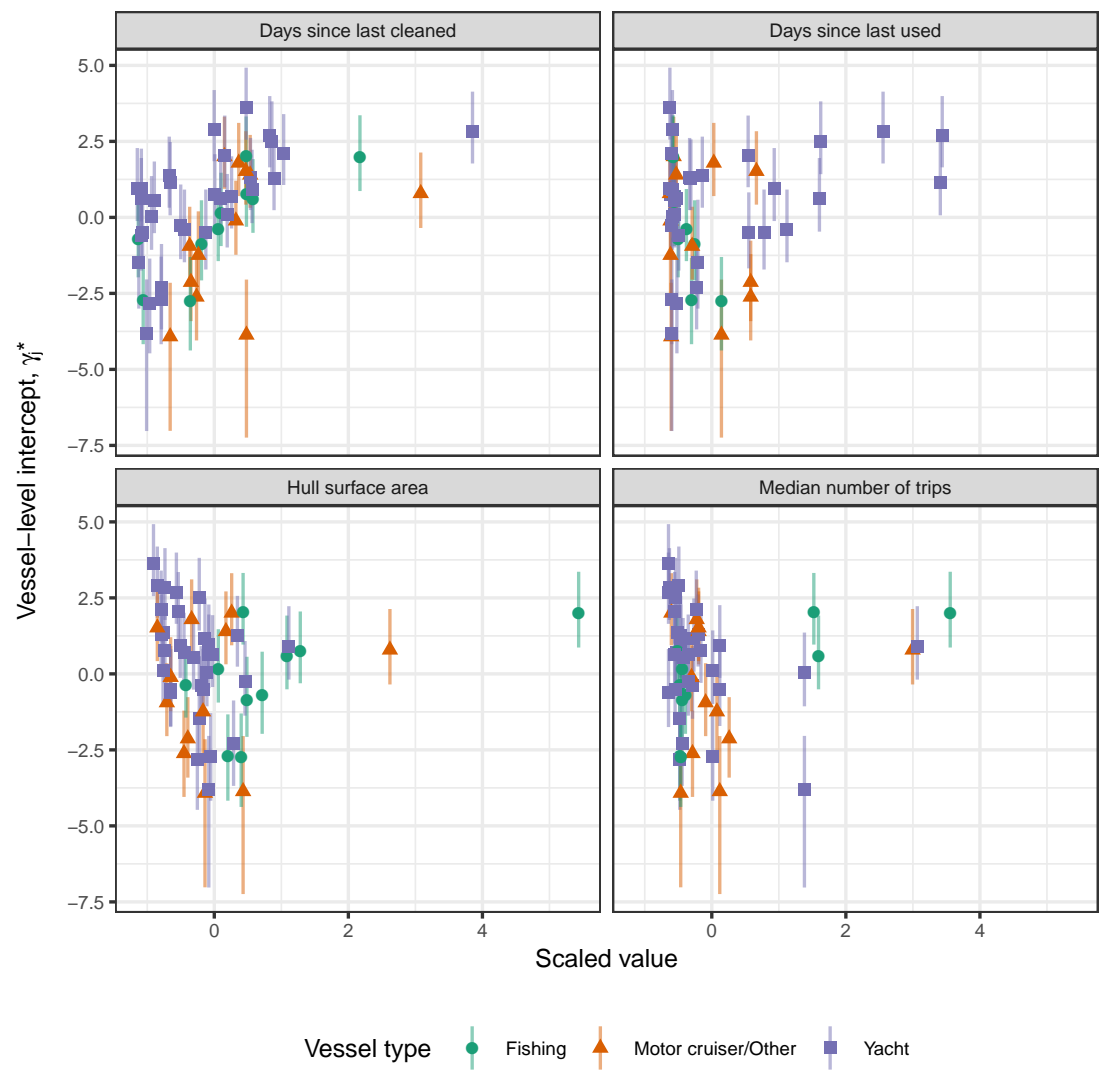

(a) Vessel-level intercepts coloured by vessel type.

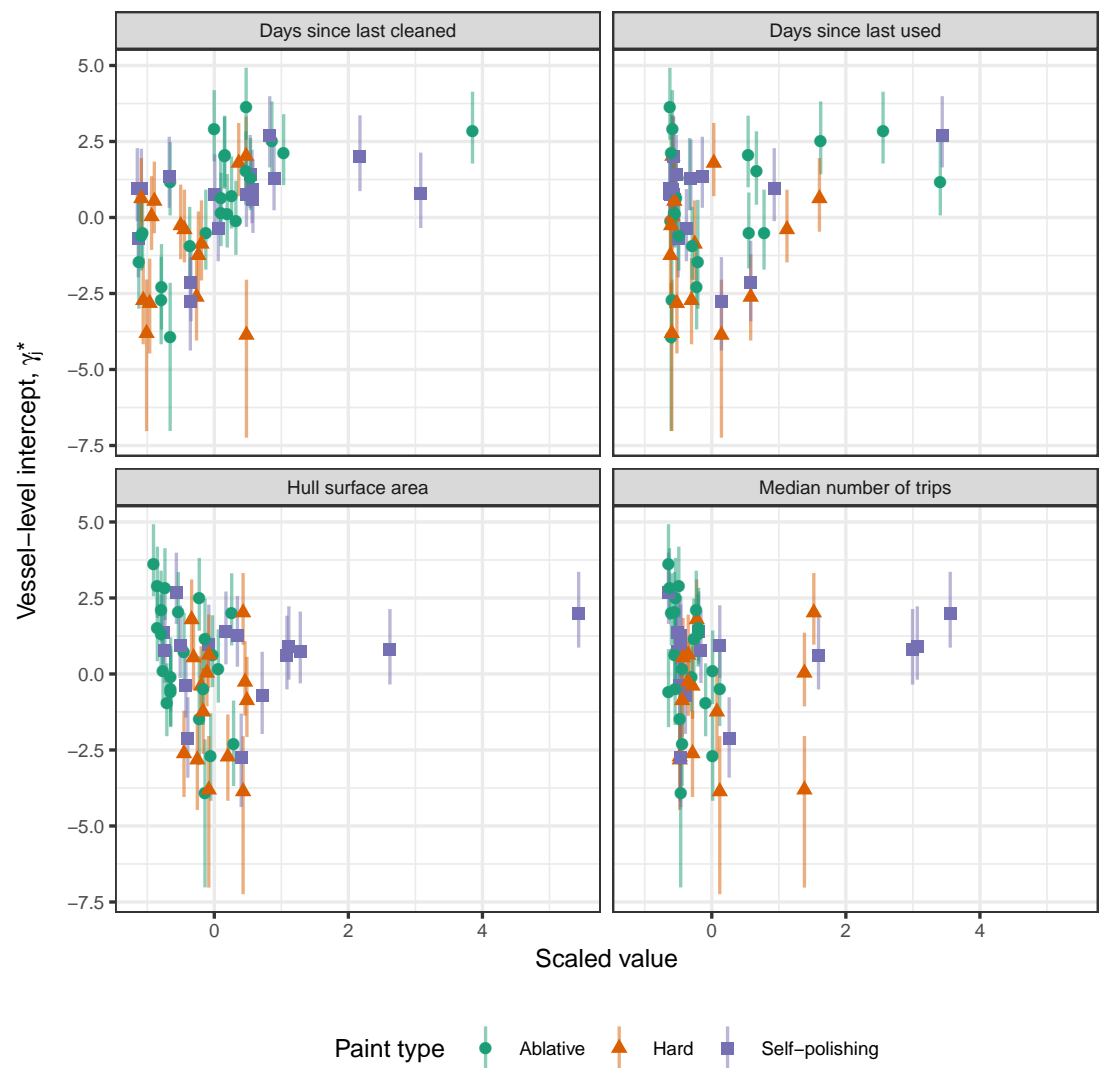

(b) Vessel-level intercepts coloured by antifouling paint type.

Figure 2: Estimated vessel-level intercepts from M1, plotted against the four ordinal predictors. Each plot shows the median and $80 \%$ credible interval, coloured by vessel type (2a) and paint type (2b). The (median) regression lines for each predictor are overlaid. 


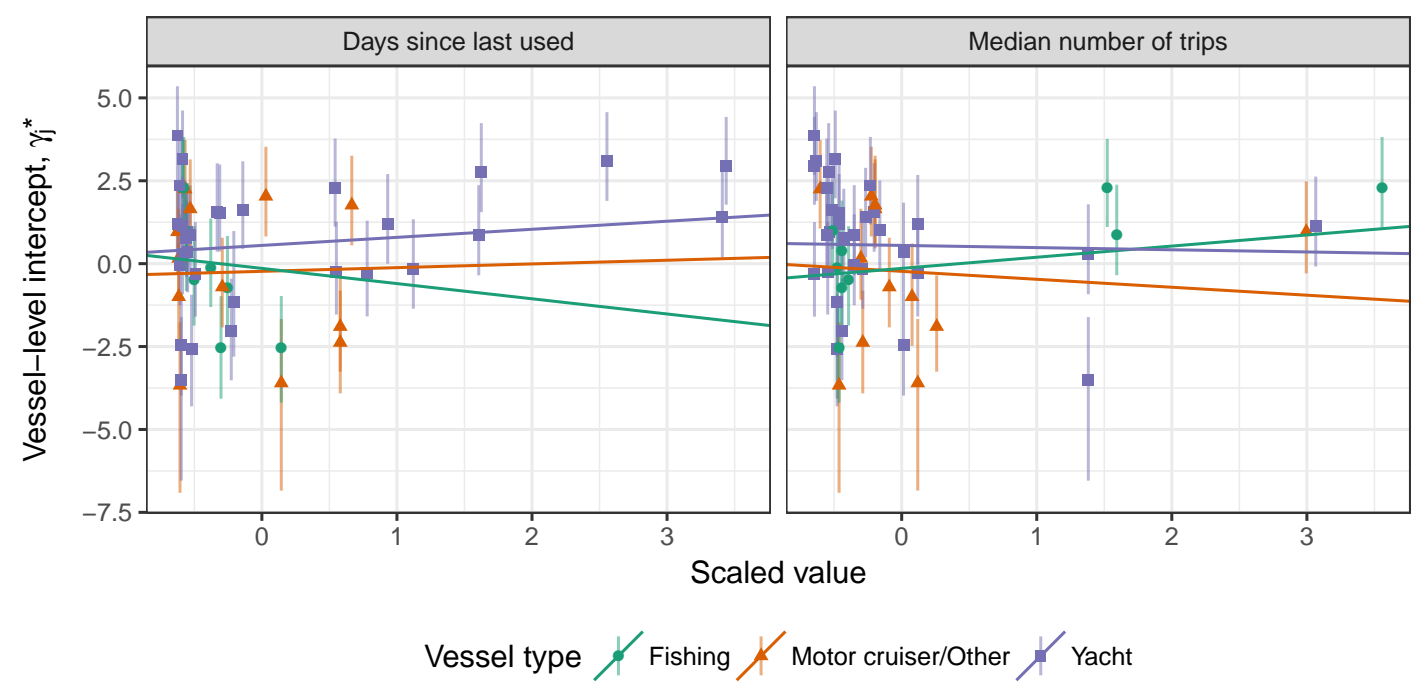

(a) Vessel-level intercepts coloured by vessel type.

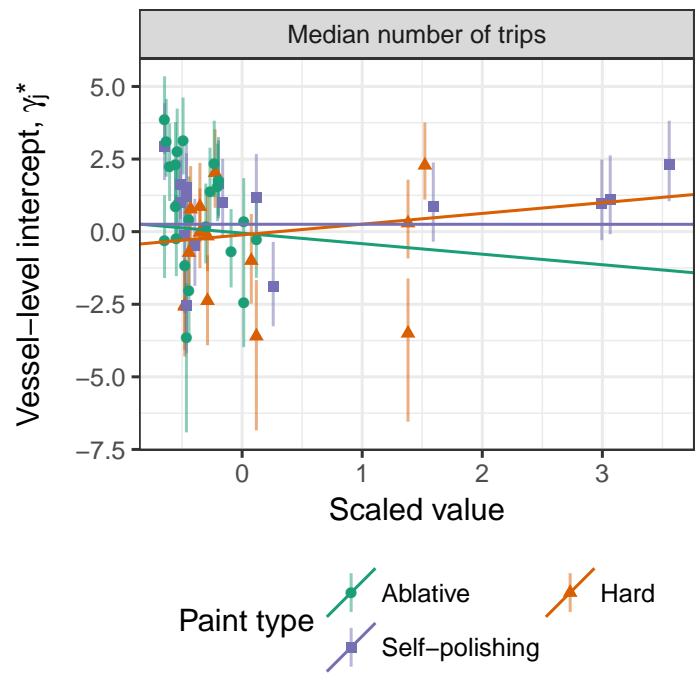

(b) Vessel-level intercepts coloured by antifouling paint type.

Figure 3: Estimated vessel-level intercepts from M2, plotted against the two ordinal predictors with interactions being assessed. Regression lines for each estimated interaction are overlaid. 

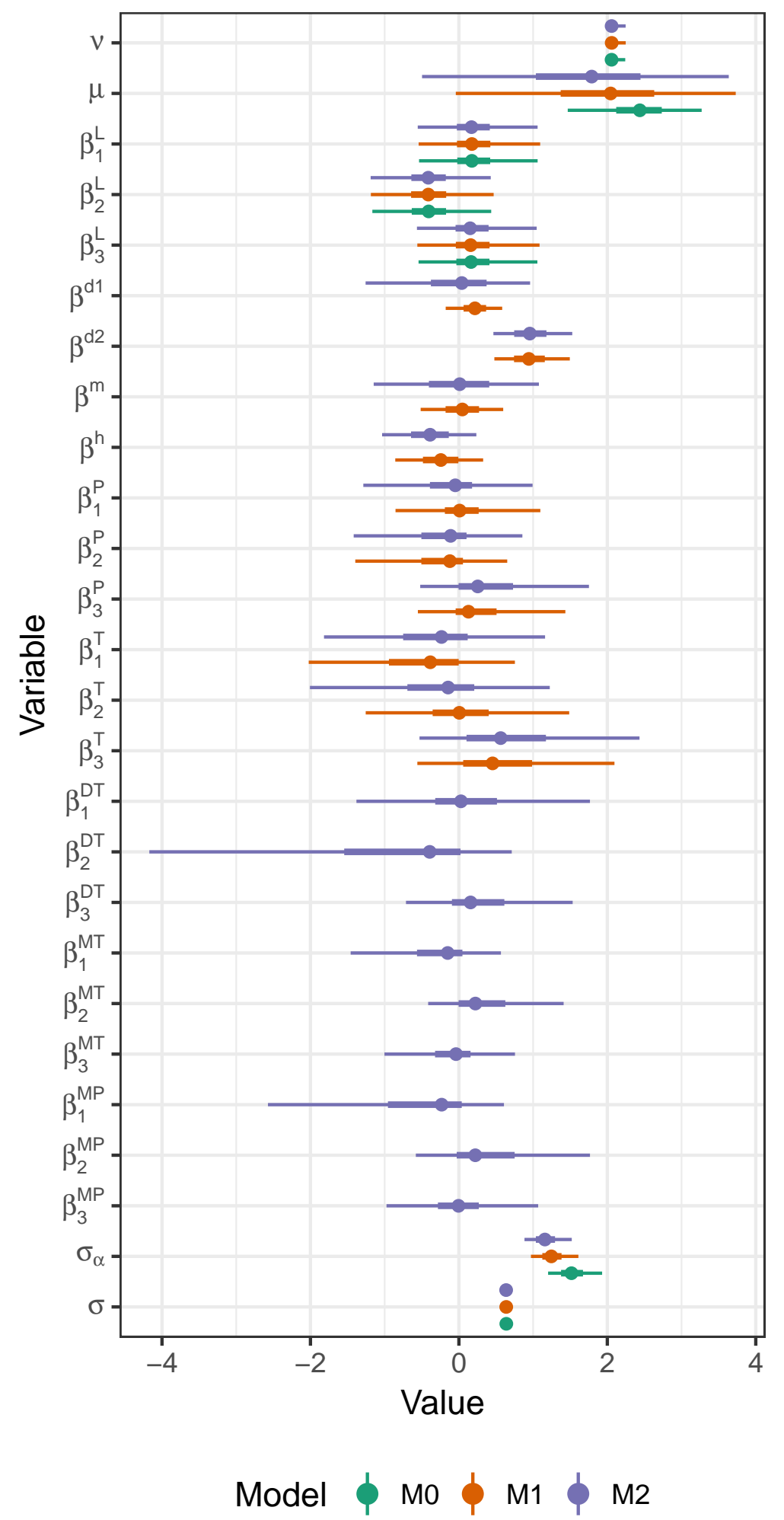

Figure 4: Estimated coefficients from $\mathrm{M} 0-\mathrm{M} 2$. Coefficients from each model (where applicable) are shown grouped within coefficient on the y-axis. The median is shown as a point estimate, with $50 \%$ and $90 \%$ credible intervals. 
bioRxiv preprint doi: https://doi.org/10.1101/248567; this version posted May 11, 2018. The copyright holder for this preprint (which was not certified by peer review) is the author/funder, who has granted bioRxiv a license to display the preprint in perpetuity. It is made available under aCC-BY-NC 4.0 International license.

\subsubsection{Predictive Model Comparison}

Table 3 compares the models by their leave-one-out information criterion (LOOIC, analogous to AIC, see Vehtari et al., 2016). M2 is the best performing model based on LOOIC, but the variability is sufficiently large that all models are closely performing. The difference in LOOIC between M0 and M2 (3.5) is almost one and a half times the standard error of the difference.

Table 3: LOOIC-based comparison of models M0-M2. The model with the smallest LOOIC (M2) is shown first, with subsequent rows ordered by increasing LOOIC (smaller LOOIC values are preferred). $\triangle$ LOOIC shows the difference in LOOIC between all models and $\mathrm{M} 2$; se $(\triangle \mathrm{LOOIC})$ shows the estimated standard error of the difference. Eff. $\mathrm{P}$ gives the estimated effective number of parameters; se(Eff. P) shows its standard error.

\begin{tabular}{lrrrrrr}
\hline Model & LOOIC & se(ELPD) & Eff. P & se(Eff. P) & $\Delta$ LOOIC & se $(\Delta$ LOOIC) \\
\hline M2 & 1102 & 21.7 & 70.2 & 4.29 & & \\
M1 & 1103 & 21.6 & 70.5 & 4.29 & 0.36 & 0.827 \\
M0 & 1106 & 21.7 & 73.3 & 4.90 & 3.55 & 2.522 \\
\hline
\end{tabular}

\section{Discussion}

Several previous studies and vessel profiling by regulatory authorities have proposed vessel characteristics that should be indicative of biofouling translocation risks, including voyage time, time in the water, time since application of antifouling paint, frequency of vessel use and stationary period (Ashton et al., 2006; Hewitt et al., 2011; Ministry for Primary Industries, New Zealand, 2016; California State Lands Commission, 2017; Department of Fisheries, Western Australia, n.d.).

Some analyses, however, have either failed to find a strong relationship between vessel characteristics and fouling extent or abundance, or provided contradictory evidence. Clarke Murray et al. (2011) for example, found percent fouling cover on recreational yachts was not related to travel frequency or the age of antifouling paint. Floerl et al. (2005) concluded that the abundance of non-indigenous species on yacht hulls could not be associated with maintenance schedules, travel history or owners maintenance behaviour. Similarly, Ashton et al. (2014) did not find significant correlations between last cleaning and extent of fouling using in-water surveys, and also concluded that the type of recreational vessel does not explain differences in biofouling patterns.

Other studies however, suggest that time since the antifouling paint was applied to the vessel is a consistently reliable predictor of biofouling (Ashton et al., 2006; Floerl et al., 2005; Lacoursière-Roussel et al., 2012b; Ashton et al., 2014), and that time in the 
water, stationary periods, and voyage types are relevant factors (Ashton et al., 2006; Lacoursière-Roussel et al., 2012b). Lacoursière-Roussel et al., 2012b also suggest that vessel type does play a role because powerboats and catamarans, for example, have a greater risk of fouling due to their higher number of niche areas.

The results presented here demonstrate relationships that are largely consistent with prior expectations about important risk factors; that is, the amount of hull fouling biomass is related to the time since a vessel was last cleaned and last used, how freple a yacht that hasn't been cleaned in 249 days. The model predicts that for such a vessel, there is a $74 \%$ probability that delaying cleaning by six months would result in an increase of wet weight biomass within a $0.5 \mathrm{~m}^{2}$ area on the hull of the vessel. This result is in agreement with recommendations of continual maintenance by the Australian and New Zealand Antifouling and In-water Cleaning Guidelines (Department of Agriculture, Canberra, 2015; Georgiades et al., 2018).

The size of the vessel, measured by the hull surface area, was found to have a small negative relationship if used to predict biofouling levels; however, the uncertainty in this estimate was relatively large. Given the same frequency of use, the modelling suggests that different types of vessels have different effects on biofouling levels. For example, assume that vessels have the same duration since last being cleaned, and the same duration since last being used; the model predicts that there is an $72 \%$ predicted probability that a yacht will have a larger wet weight biomass within a $0.5 \mathrm{~m}^{2}$ area than the motor cruiser/other vessel; compared to a fishing vessel, this probability is $75 \%$.

A weak varying effect of the median number of trips taken by the vessel per year and paint type was found in the model. The limited number of data points at the vessel level (53) hampered the precision of estimating these effects, but the direction of effects conforms with prior expectations, namely that: both ablative and self-polishing paints are reliant on the vessel being used in order to be effective, whilst hard paints are less so (Georgiades et al., 2018).

There is also evidence that the location of the sample is an important predictor for the wet weight of biomass. Figure 4 shows a consistent result that the wet weight of biomass when sampled along the hull $\left(\beta_{1}^{L}\right)$, is no different to samples made from the rudder $\left(\beta_{3}^{L}\right)$. Measurements made on samples from the keel however, are generally smaller than those made along either the hull or on the rudder; in fact, there is a $69 \%$ predicted probability of this being the case. This is not a characteristic of vessels, and thus cannot be used for management purposes; the location of the measurement does however need to be considered in any future work, and in particular may restrict vessel-level summaries of wet weight of biomass being analysed (for example, total 
wet weight of biomass).

Fouling cover on vessels can be up to ten times higher in niche areas than on hulls (Clarke Murray et al., 2011), and these areas represent important settlement locations of non-indigenous species (Lacoursière-Roussel et al., 2012b; Zabin et al., 2014). Floerl et al. (2010) and Ashton et al. (2014) agree on the importance of targeting niche areas for vessel surveys and sampling.

This study is not without its limitations. We found that the (log-transformed) wet weight of biomass found on small vessels was best described by a $t$-distribution. Posterior predictive checks showed that the analysis regression models generated data consistent with the observed data for the interquartile range, but less so for the median and proportion of observations below the limit of detection. A possible approach to allow for the larger number of censored observations than expected would be to fit a mixture model. It is not directly clear how this would work however, when vessels may contain some samples measured below and some above the limit of detection. Further, given the limited data available, it was considered that an attempt to fit such a mixture model was unfeasible.

The small number of vessels sampled also limits the precision at which we can estimate the effect of vessel-level characteristics, and in particular, any interactions between them. We demonstrated a number of possible interaction effects, yet the error in those estimates was found to be relatively large. The nature of these varying effects however, did conform to prior expectations of the direction of the effect; it is the size of such effects that is not known with a high degree of certainty.

Sample size reservations notwithstanding, we have confirmed that vessel-level characteristics can be used to predict the amount of wet weight of fouling biomass that may be present on small vessels in Australia. The development of such predictive tools could aid authorities in assessing the risk posed by individual vessels and classifying those that are a risk of having high levels of fouling will potentially reduce the introduction and spread of invasive species (Minchin et al., 2006; Clarke et al., 2017).

The results suggest that in particular, owners of small vessels should be encouraged to apply an antifouling paint that is appropriate to their vessel operational profile and to maintain a regular cleaning and maintenance schedule in accordance with the manufacturer's instructions as per Australian and New Zealand guidance (Department of Agriculture, Canberra, 2015; Georgiades et al., 2018). Management interventions, such as diver inspections, directive to clean at a dry dock etc, can be implemented to varying degrees based on increasing levels of risk, but also with a prohibitive increase in resources, cost and time (Campbell and Hewitt, 2011). Therefore strategies and incentives could be investigated to encourage vessel owners to improve their cleaning and 
maintenance, as well as education and outreach programs for vessel owners to increase awareness of invasive species and their impacts (Brine et al., 2013; Minchin et al., 2006).

Authorities could also introduce regulated antifouling paint regimes, e.g. every 12 months, regular inspections and providing cleaning facilities for recreational vessel users (Zabin et al., 2014).

Preventing the introduction of invasive marine species is the key to reducing their spread, requiring stringent implementation of measures to reduce invasions through all vector routes (Bax et al., 2001; Inglis et al., 2013; Sinner et al., 2013). While interregional movements of vessels are not without risk, minimising species translocations will require a relevant and transparent risk based profilinf and assessment (Campbell and Hewitt, 2011; Clarke et al., 2017), taking into account the characteristics of transport vectors (Floerl and Inglis, 2005). Such profiling and assessment would be assisted by promoting ongoing maintenance and consistent "clean before you leave" messaging within a broader domestic pathway management approach.

\section{${ }_{411}$ Acknowledgements}

The authors would like to acknowledge Dr Enamul Kabir for his contribution to earlier analyses that were not a part of this manuscript, and to Sandringham College,

Melbourne, Victoria, for use of the school's laboratory space to process the samples taken within Melbourne. AR, SL and TH's contributions were funded in part by the Centre of Excellence for Biosecurity Risk Analysis. 
bioRxiv preprint doi: https://doi.org/10.1101/248567; this version posted May 11, 2018. The copyright holder for this preprint (which was

\section{${ }_{417}$ References}

Acosta, Hernando, Dongrui Wu, and Barrie M Forrest (2010). “Fuzzy experts on recreational vessels, a risk modelling approach for marine invasions". In: Ecological mod-

420 elling 221.5, pp. 850-863. ISSN: 0304-3800.

Ashton, Gail V, Karin Boos, Richard Shucksmith, and Elizabeth J Cook (2006). "Risk assessment of hull fouling as a vector for marine non-natives in Scotland". In: Aquatic invasions / European Research Network on Aquatic Invasive Species 1.4, pp. 214-218. ISSN: 1818-5487.

Ashton, Gail, Ian Davidson, and Gregory Ruiz (2014). "Transient small boats as a longdistance coastal vector for dispersal of biofouling organisms". In: Estuaries and Coasts 37.6, pp. 1572-1581. ISSN: 1559-2723.

Bax, N, J T Carlton, A Mathews-Amos, R L Haedrich, F G Howarth, J E Purcell, A Rieser, and A Gray (2001). "The control of biological invasions in the world's oceans". In: Conservation biology: the journal of the Society for Conservation Biology 15.5, pp. 12341246. ISSN: 0888-8892, 1523-1739.

Brine, Oriana, Lou Hunt, and Mark John Costello (2013). "Marine biofouling on recreational boats on swing moorings and berths". In: Management of Biological Invasions 4.4, pp. 327-341. ISSN: 1989-8649.

Burgin, Shelley and Nigel Hardiman (2011). "The direct physical, chemical and biotic impacts on Australian coastal waters due to recreational boating". In: Biodiversity and conservation 20.4, pp. 683-701. ISSN: 0960-3115.

Buuren, Stef van and Karin Groothuis-Oudshoorn (2011). "mice: Multivariate Imputation by Chained Equations in R". In: Journal of statistical software 45.3, pp. 1-67. ISSN: 1548-7660.

California State Lands Commission (2017). Marine Invasive Species Program Annual Vessel Reporting Form. http://www.slc.ca.gov/Eorms/MISP/Annual_vessel_ Reporting_Form.pdf. Accessed: 2018-3-NA.

Campbell, Marnie L and Chad L Hewitt (2011). "Assessing the port to port risk of vessel movements vectoring non-indigenous marine species within and across domestic Australian borders". In: Biofouling 27.6, pp. 631-644. ISSN: 0892-7014.

Carlton, James T and Jonathan B Geller (1993). "Ecological roulette: the global transport of nonindigenous marine organisms". In: Science 261.5117, pp. 78-82. ISSN: 00368075.

so Clarke Murray, Cathryn, Evgeny A Pakhomov, and Thomas W Therriault (2011). "Recreational boating: a large unregulated vector transporting marine invasive species". In: Diversity and Distributions 17.6, pp. 1161-1172. ISSN: 1472-4642.

Clarke, Sandy, Tracey Hollings, Nianjun Liu, Greg Hood, and Andrew Robinson (2017). "Biosecurity risk factors presented by international vessels: a statistical analysis". 
bioRxiv preprint doi: https://doi.org/10.1101/248567; this version posted May 11, 2018. The copyright holder for this preprint (which was not certified by peer review) is the author/funder, who has granted bioRxiv a license to display the preprint in perpetuity. It is made available under aCC-BY-NC 4.0 International license.

Gelman, Andrew and Jennifer Hill (2007). Data Analysis Using Regression and Multilevel/Hierarchical Models. en. Cambridge: Cambridge University Press. ISBN: 9780511790942.

Gelman, Andrew and Donald B Rubin (1992). "Inference from Iterative Simulation Using Multiple Sequences". In: Statistical science: a review journal of the Institute of Mathematical Statistics 7.4, pp. 457-472. ISSN: 0883-4237.

Georgiades, Eugene, Abraham Growcott, and Daniel Kluza (2018). Technical Guidance on Biofouling Management for Vessels Arriving to New Zealand. Tech. rep. 2018/07. Ministry for Primary Industries, New Zealand.

Georgiades, Eugene and Daniel Kluza (2017). “Evidence-Based Decision Making to Underpin the Thresholds in New Zealand's Craft Risk Management Standard: Bio-

Department of Agriculture, Canberra (2015). Department of the Environment and New Zealand Ministry for Primary Industries (2015), Anti-fouling and in-water cleaning guidelines. Tech. rep.

Department of Fisheries, Western Australia (n.d.). Biofouling Risk Assessment Tool.

Accessed: 2018-3-NA.

evaluating options for ballast-water management". In: Proceedings of the Royal Society of London B: Biological Sciences 271.1539, pp. 575-580. ISSN: 0962-8452. tion between source populations and human transport vectors". In: Biological invasions 7.4, pp. 589-606. ISSN: 1387-3547.

tool to prevent accidental introductions of nonindigenous marine species". In: Environmental management 35.6, pp. 765-778. ISSN: 0364-152X.

vessel hull inspections and assessment of biosecurity risks to the Kermadec and sub-Antarctic islands regions. Tech. rep. CHC2010-086. National Institute of Water and Atmospheric

Food and Agriculture Organization of the United Nations (2016). The State of World Fisheries and Aquaculture 2016. Contributing to Food Security and Nutrition for All. spread of marine pests: insights from management of the Asian kelp Undaria pinnatifida and colonial ascidian Didemnum vexillum". In: Management of Biological InDOI: $10.1017 /$ CBO9780511790942. fouling on Vessels Arriving to New Zealand". In: Marine Technology Society Journal

en. In: Biological invasions 19.10, pp. 2837-2850. ISSN: 1387-3547, 1573-1464. DOI: 10 . 51.2, pp. 76-88. ISSN: 0025-3324. 
bioRxiv preprint doi: https://doi. org/10.1101/248567; this version posted May 11, 2018. The copyright holder for this preprint (which was not certified by peer review) is the author/funder, who has granted bioRxiv a license to display the preprint in perpetuity. It is made available under aCC-BY-NC 4.0 International license.

Hayes, Keith R, Rasanthi Gunasekera, Jawahar Patil, Cath Sliwa, Sasha Migus, Felicity McEnnulty, Piers Dunstan, Mark Green, and Caroline Sutton (2007). Empirical validation: Small vessel translocation of key threatening species. Australian Government Natural Heritage Trust Project 46630. CSIRO. ISBN: 9781921232534.

Hewitt, Chad L, Marnie L Campbell, and Britta Schaffelke (2007). “Introductions of seaweeds: accidental transfer pathways and mechanisms". In: Botanica marina 50.5/6, pp. 326-337. ISSN: 0006-8055, 1437-4323.

Hewitt, Chad L, Marnie L Campbell, Ronald E Thresher, Richard B Martin, Sue Boyd, Brian F Cohen, David R Currie, Martin F Gomon, Michael J Keough, and John A Lewis (2004). “Introduced and cryptogenic species in Port Phillip Bay, Victoria, Australia". In: Marine biology 144.1, pp. 183-202. ISSN: 0025-3162.

Hewitt, Chad, Marnie Campbell, Ashley Coutts, Alisha Dahlstrom, Derek Shields, and Joseph Valentine (2011). Species Biofouling Risk Assessment. Tech. rep. Department of Agriculture, Fisheries and Forestry, Australia.

Hulme, Philip E (2009). "Trade, transport and trouble: managing invasive species pathways in an era of globalization". In: The Journal of Applied Ecology 46.1, pp. 10-18. ISSN: 0021-8901, 1365-2664. DOI:

Inglis, Graeme J, Oliver Floerl, and Chris Woods (2012). Scenarios of vessel fouling risk and their management: an evaluation of options. Tech. rep. 2012/07. Ministry of Agriculture and Forestry, New Zealand. DOI:

Inglis, Graeme J, Don Morrisey, Chris Woods, Jim Sinner, and Mark Newton (2013). Managing the domestic spread of harmful marine organisms. Part A: operational tools for management. Tech. rep. CH2013-150. Ministry for Primary Industries, New Zealand.

International Maritime Organization (2011). Guidelines for the control and management of ships' biofouling to minimize the transfer of invasive aquatic species. Tech. rep. Annex 26, Resolution MEPC.207(62).

- (2012). Guidance for minimizing the transfer of invasive aquatic species as biofouling (hull fouling) for recreational craft. Tech. rep. MEPC.1/Circ.792.

- (2017). International Convention for the Control and Management of Ships' Ballast Water and Sediments (BWM). and-Management-of-Ships' - Ballast-Water-and-Sediments-(BWM) . aspx. Accessed: 2018-3-NA.

- (n.d.). Shipping routes and trade intensification. Environment/Biofouling/Pages/default.aspx. Accessed: 2018-3-NA.

Lacoursière-Roussel, Anaïs, Dan G Bock, Melania E Cristescu, Frederic Guichard, Philippe Girard, Pierre Legendre, and Christopher W McKindsey (2012a). “Disentangling invasion processes in a dynamic shipping-boating network". In: Molecular ecology 21.17, pp. 4227-4241. ISSN: 0962-1083, 1365-294X. 
bioRxiv preprint doi: https://doi.org/10.1101/248567; this version posted May 11, 2018. The copyright holder for this preprint (which was

Lacoursière-Roussel, Anaïs, Barrie M Forrest, Frédéric Guichard, Richard F Piola, and Christopher W McKindsey (2012b). “Modeling biofouling from boat and source characteristics: a comparative study between Canada and New Zealand". In: Biological invasions 14.11, pp. 2301-2314. ISSN: 1387-3547.

Lott, M J and K Rose (2016). “Emerging threats to biosecurity in Australasia: the need for an integrated management strategy". en. In: Pacific conservation biology: a journal devoted to conservation and land management in the Pacific region 22.2, pp. 182-188. ISSN: 1038-2097, 2204-4604. DOI: 10.1071 / PC15040.

Minchin, Dan, Oliver Floerl, Dario Savini, and Anna Occhipinti-Ambrogi (2006). "Small craft and the spread of exotic species". In: The ecology of transportation: managing mobility for the environment. Ed. by John Davenport and Julia L Davenport. Dordrecht: Springer, pp. 99-118. ISBN: 9781402045042.

Ministry for Primary Industries, New Zealand (2016). Biofouling and Ballast Water Declaration. http: / / www . mpi govt.nz/importing / border-clearance / vessels/arrival-process-steps/forms-and-templates/. Accessed: 2018-3-NA.

Molnar, Jennifer L, Rebecca L Gamboa, Carmen Revenga, and Mark D Spalding (2008). "Assessing the global threat of invasive species to marine biodiversity". In: Frontiers in ecology and the environment 6.9, pp. 485-492. ISSN: 1540-9295, 1540-9309. DOI: 10 .

Paini, Dean R and Denys Yemshanov (2012). "Modelling the arrival of invasive organisms via the international marine shipping network: a Khapra beetle study". In: PloS one 7.9, e44589. ISSN: 1932-6203.

Piola, Richard F and Justin I McDonald (2012). "Marine biosecurity: The importance of awareness, support and cooperation in managing a successful incursion response". In: Marine pollution bulletin 64.9, pp. 1766-1773. ISSN: 0025-326X.

R Core Team (2017). R: A Language and Environment for Statistical Computing. R Foundation for Statistical Computing. Vienna, Austria.

Rubin, Donald B (1996). "Multiple Imputation after 18+ Years". In: Journal of the American Statistical Association 91.434, pp. 473-489. ISSN: 0162-1459. DOI: $10.1080 / 01621459$. 1996.10476908.

Ruiz, Gregory M, James T Carlton, Edwin D Grosholz, and Anson H Hines (1997). "Global invasions of marine and estuarine habitats by non-indigenous species: mechanisms, extent, and consequences". In: American zoologist 37.6, pp. 621-632. ISSN: 0003-1569, 1540-7063.

Sim-Smith, Carina, Stacey Faire, and Annette Lees (2016). Managing Biosecurity Risk for Business Benefit. Tech. rep. 2016/14. Ministry for Primary Industries, New Zealand. 
bioRxiv preprint doi: https://doi. org/10.1101/248567; this version posted May 11 2018. The copyright holder for this preprint (which was

Sinner, Jim, Barrie Forrest, Mark Newton, Grant Hopkins, Graeme J Inglis, Chris Woods, and Don Morrisey (2013). Managing the domestic spread of harmful marine organisms, Part B: Statutory framework and analysis of options. Tech. rep. 2442. Cawthron Institute. Stan Development Team (2016). Stan Modeling Language Users Guide and Reference Manual.

Thresher, Ronald E (1999). "Diversity, impacts and options for managing invasive marine species in Australian waters". In: Australian Journal of Environmental Management 6.3, pp. 137-148. ISSN: 1322-1698.

Vehtari, Aki, Andrew Gelman, and Jonah Gabry (2016). "Practical Bayesian model evaluation using leave-one-out cross-validation and WAIC". en. In: Statistics and computing, pp. 1-20. ISSN: 0960-3174, 1573-1375. DOI: $9696-4$.

Vitousek, Peter M, Carla M D'Antonio, Lloyd L Loope, and Randy Westbrooks (1996). "Biological invasions as global environmental change". In: American scientist 84.5, pp. 468-478. ISSN: 0003-0996.

Willan, Richard C, Barry C Russell, Nicolas B Murfet, Kirrily L Moore, Felicity R McEnnulty, Suzanne K Horner, Chad L Hewitt, Gavin M Dally, Marnie L Campbell, and Sean T Bourke (2000). “Outbreak of Mytilopsis sallei (Récluz, 1849) (Bivalvia: Dreissenidae) in Australia". In: Molluscan research 20.2, pp. 25-30. ISSN: 1323-5818. DOI: $10.1080 / 13235818.2000 .10673730$.

Zabin, Chela J, Gail V Ashton, Christopher W Brown, Ian C Davidson, Mark D Sytsma, and Gregory M Ruiz (2014). "Small boats provide connectivity for nonindigenous marine species between a highly invaded international port and nearby coastal harbors". In: Manag Biol Invasions 5.2, pp. 97-112.

Zhou, Xiang and Jerome P Reiter (2010). "A Note on Bayesian Inference After Multiple Imputation". In: The American statistician 64.2, pp. 159-163. ISSN: 0003-1305. DOI: 10 . eprint: 